\title{
ASSESSING FLOOD DAMAGE TO AGRICULTURE USING COLOR INFRARED AERIAL PHOTOGRAPHY
}

An Example From the 1975 Red River Valley Flood of North Dakota and Minnesota

BY WILLIAM H. ANDERSON

OPEN-FILE REPORT 77-175 

UNITED STATES

DEPARTMENT OF THE INTERIOR

GEOLOGICAL SURVEY

ASSESSING FLOOD DAMAGE TO AGRICULTURE USING

COLOR INFRARED AERIAL PHOTOGRAPHY

An Example From the 1975 Red River

Valley Flood of North Dakota and Minnesota

By William H. Anderson

Open-File Report 77-175

EROS Data Center

Sioux Falls, South Dakota, 57198

1977

RETURN TO:

fun nerenomy om befan 


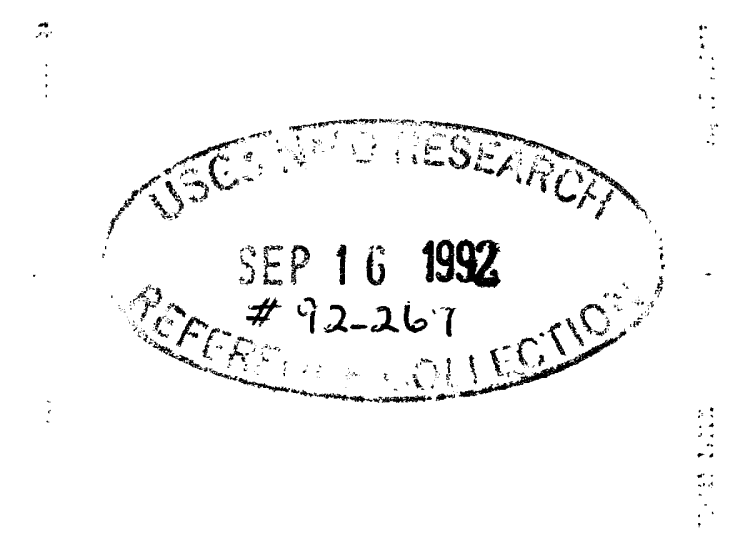


CONTENTS

Page

Abstract-- 1

Introduction-- 1

Background Information: The Red River Valley Flood------ 2

Aerial Photographic Coverage of the Red River Flood------- 5

Color Infrared Film- 15

Application Example: Using CIR Photography for

Determining Crop Acreage Loss- 17

Conclusions- 27

Literature Cited and Selected Additional References------- 28 



\section{ILLUSTRATIONS 1 /}

Page

Figure 1. Map showing rainfall distribution for 1975

Red River Valley Flood-_-

2. Landsat image showing regional extent of flooding---_--

3. Small scale color infrared aerial photograph of flooded landscape southwest of

Fargo, N. Dak.-

4. Small scale color infrared aerial photograph of region north of Fargo, N. Dak.

5. Medium scale color infrared aerial photograph of area southwest of Fargo, N. Dak.

6. Medium scale color infrared aerial photograph of area north of Fargo, N. Dak.-

7. Medium scale color infrared aerial photograph of non-flooded landscape-

8. Hand-held color infrared aerial oblique-- -

9. Location map for aerial photographs provided as examples--

10. Diagram showing photographic coverage scale relationships-C-

11. Normal color and color infrared film spectral sensitivity diagram--_-_-_-

12. Aerial photograph of demonstration site with accompanying field annotation guide--

13. Ground photograph illustrating typical appearance of flooded fields in vicinity of demonstration site-_-_-_-_-

14. Photographs and overlays illustrating alternative interpretation procedures------- 

Figure 15. Field sketch and photograph comparing conventional appraisal method with aerial photograph interpretation method

of damage assessment--

$1 /$ The color illustrations in this document have been altered slightly from their original scale due to limitations of the color xerox process. However, all illustrations are available in $35 \mathrm{~mm}$ transparency format from: User Services Branch EROS Data Center Sioux Falls, SD 57198

The reference numbers which must be used in ordering are:

Figure Number

1

2

3

4

5.

6

7

8 $\underline{\text { Ref Number }}$

PA05208

PA05209

PA05210

PA05211

PA05212

PA05213

PA05214

PA05215
Figure Number

9

10

11

12

13

14

15 $\underline{\text { Ref Number }}$

PA05216

PA05217

PA05218

PA05219

PA05220

PA05221

PAO5 222

\section{TABLES}

Page

24

Table 1. Results of interpretation- 



\author{
ASSESSING FLOOD DAMAGE TO AGRICULTURE USING \\ COLOR INFRARED AERIAL PHOTOGRAPHY \\ An Example From the 1975 Red River Valley Flood \\ of North Dakota and Minnesota
}

By William H. Anderson

Technicolor Graphic Services, Inc. 1 /

EROS Data Center

\begin{abstract}
The rationale for using color-infrared (CIR) film to assist in assessing flood damage to agriculture is demonstrated using examples prepared from photographs acquired of the 1975 flood in the Red River Valley of North Dakota and Minnesota. Information concerning flood inundation boundaries, crop damage, soil erosion, sedimentation, and other similar general features and conditions was obtained through the interpretation of CIR aerial photographs. CIR aerial photographs can be used to help improve the estimates of potential remaining production on a field by field basis, owing to the increased accuracy obtained in determining the area component of crop production as compared to conventional ground sketching methods.
\end{abstract}

\title{
INTRODUCTION
}

Color infrared photography is a powerful tool in helping to assess the damage which results from flooding in an agricultural region. Although the techniques of airphoto interpretation are not new, their practical application to assessing flood damage to agriculture is not well documented. Most of the literature which describes potentially useful procedures appears in technical publications such as Photogrammetric Engineering and Remote Sensing, which are generally not well known outside of the scientific research community.

I/ Sponsored by the U.S. Geological Survey Contract Number 14-08-0001-16439. 

This report was designed to:

1) provide a general introduction to the manner in which flood related phenomena (inundation, siltation, crop destruction, etc.) appear on color-infrared (CIR) photographs using examples prepared from imagery of the 1975 Red River Valley Flood of North Dakota and Minnesota, and;

2) illustrate procedures for using CIR photographs to determine crop stand loss on individual fields.

\section{BACKGROUND INFORMATION: THE RED RIVER VALLEY FLOOD}

Because each flood is different, it is appropriate to provide a brief description of the circumstances surrounding the 1975 Red River Flood as a prelude to discussing techniques for assessing the resultant damage.

The Red River Valley was once a large glacial lake occupying the territory between what are now the States of North Dakgta and Minnesota. Most of this 15,700 square mile $\left(40,700 \mathrm{~km}^{2}\right)$ area is extremely flat and is nearly all under cultivation. The fine textured soils in the valley were derived from ancient lake sediments. Due to relatively low soil permeability and poor natural drainage gradient, artificial drainage is required in many areas to remove the water which tends to accumulate on the surface. (U.S. Dept. of Agric., 1971).

The average annual rainfall for the Red River Valley is about 20 inches $(510 \mathrm{~mm})$, but the region is noted for experiencing wide fluctuations in annual and seasonal precipitation from year to year. For example, 1975 was wetter than normal during the early spring months, and soil moisture was reported by the Department of Agriculture as plentiful. By mid-June, the southern part of the Valley had experienced additional above-average rainfall which totally saturated the soil in many areas. During the period between July 28 and July 2, extremely heavy rains fell on portions of the Valley, as summarized by the rainfall distribution map in Figure 1 (Lindskov, 1975). One station in North Dakota registered 20 inches $(510 \mathrm{~mm})$ of rainfall during the 3-day period, an amount equal to that area's total yearly average (Lindskov, 1975). Streams overflowed their banks and rain accumulated where it fell on the saturated fields. The regional extent of flooding was recorded on images acquired by Landsat-2 on July 5, 1975, as shown in Figure 2 .

The flooding situation was monitored by numerous organizations and general accounts of the flood appeared in newspapers and other media sources. Initial reports of damage made by the Agricultural Stabilization and Conservation Service (ASCS) estimated crop losses in excess of 1.3 million acres 


\section{RAINFALL DISTRIBUTION}

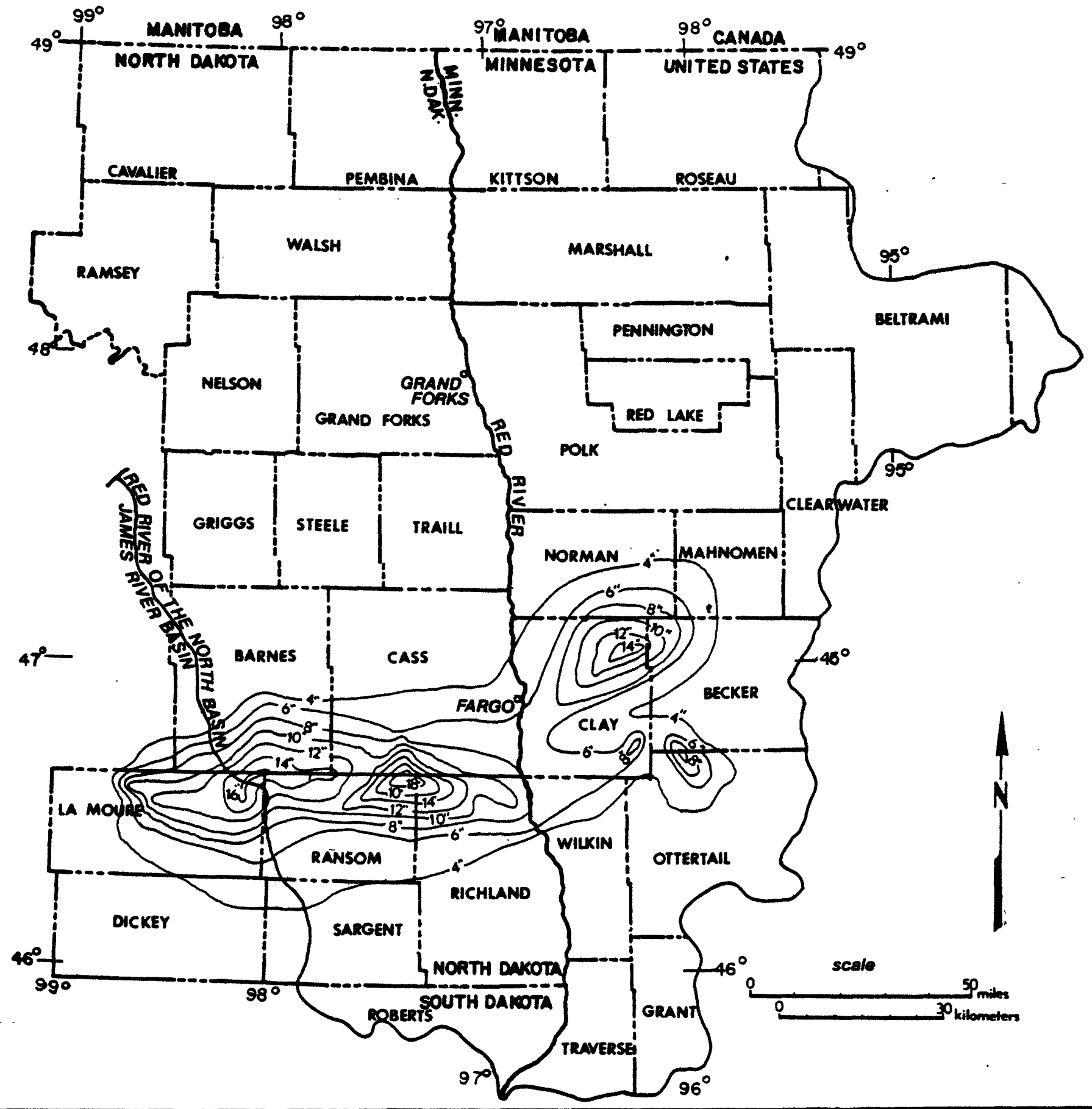

Figure 1. Amount and distribution of precipitation in the lower part of the Red River Valley during June 28 - July 2, 1975 (Lindskov, 1975). Notice the extremely heavy rainfall to the northeast of Fargo, N. Dak. 



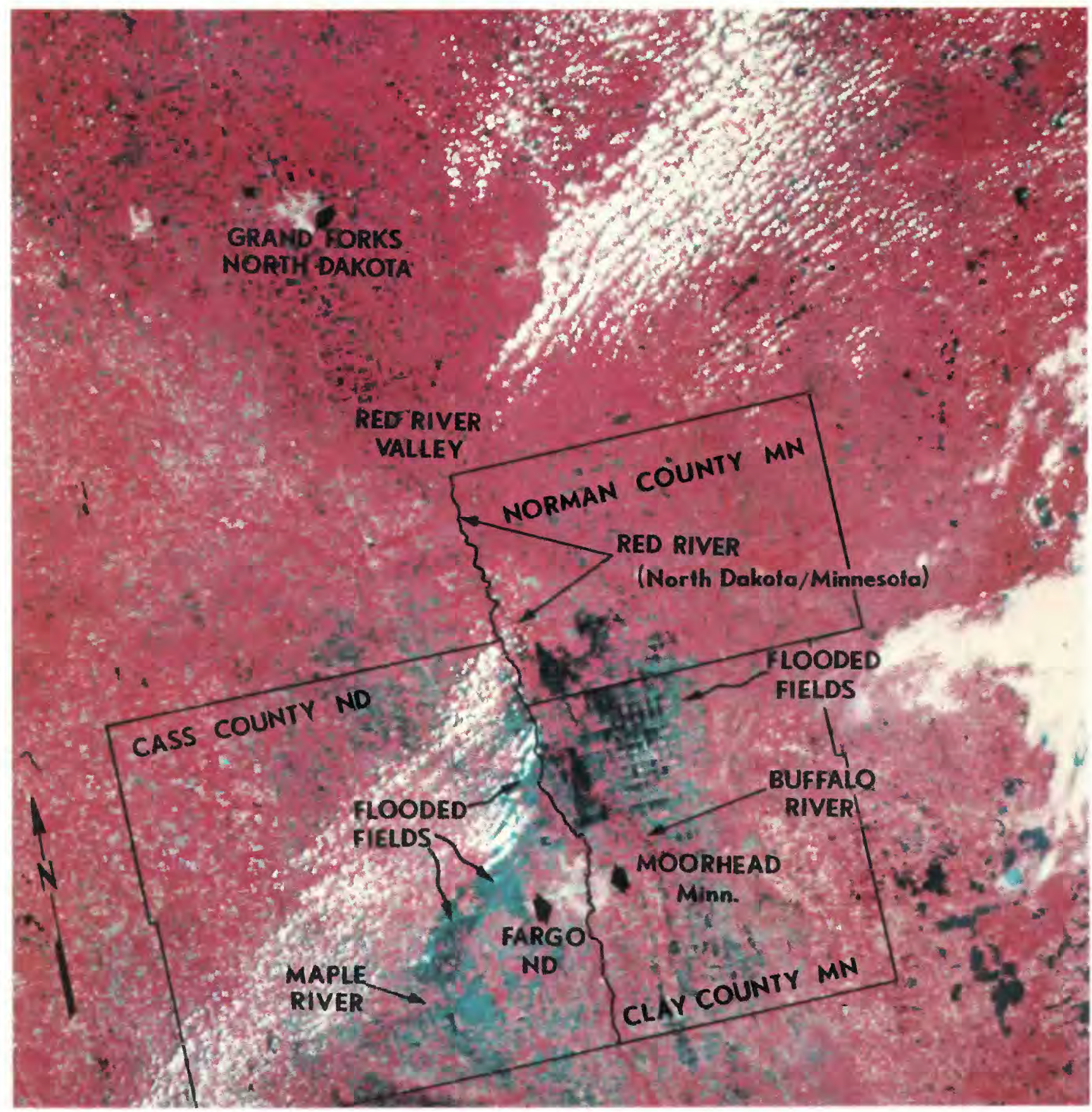

Figure 2. The general location of the 1975 Red River Valley Flood on July 5, 1975 is shown on this Landsat image (ID No. 216416372), scale 1:1,000,000. Flooded fields north and west of the city of Fargo, N. Dak., appear as dark tones in the lower center portion of the annotated image. Compare the flooded area as seen in the Landsat image with the high rainfall areas shown in Figure 1. Notice how the inundated areas do not coincide exactly with the precipitation isolines due to water movement in the 3-day period since the rain stopped. 
( $526,000 \mathrm{ha})$ and monetary losses to the agriculture community of over 171 million dollars. The U.S. Army Corps of Engineers estimated total flood damage in the Valley at 275 million dollars. More specific accounts of damage were compiled from data supplied jointly by the U.S. Weather Service, the Statistical Reporting Service (SRS) of the United States Department of Agriculture, and the County Extension Agents of the North Dakota State University and appeared in the weekly North Dakota Weather-Crop Report.

Flooding in the Red River Valley initiated efforts by several official agricultural organizations to gather timely information about the effects of excess water on agricultural production. For purposes of preliminary damage assessment, answers were sought to such questions as:

- What areas have been flooded?

- How many acres of agricultural land have been damaged?

- How badly was crop production affected?

The initial damage estimates released by the U.S. Army Corps of Engineers and the North Dakota ASCS office, were based principally on visual observations of the flooded landscape. Although their estimates were serious attemps to assess the flood's magnitude and represented the best available information at the time, those individuals responsible readily concede that early damage assessment is an extremely difficult task.

The North Dakota Crop and Livestock Reporting Service sought early information about crop loss in order to revise, if warranted, county production estimates. The Soil Conservation Service was interested in determining the extent of soil erosion. Other organizations such as The Federal Crop Insurance Corporation and the Program Compliance Office of the ASCS, required specific information, including damage to the nearest acre for insurance purposes.

AERIAL PHOTOGRAPHIC COVERAGE OF THE RED RIVER FLOOD

Aerial photography can be obtained in many forms and formats, ranging from extremely high-altitude photographs, each covering hundreds of square miles, to very low-altitude photographs 
on which individual small plants can be examined. Aerial photography of the Red River Flood ranged from $1: 116,000$ scale (1 $\mathrm{cm}=1.16 \mathrm{~km})$, high-altitude imagery to medium-scale $1: 24,000$ (1 $\mathrm{cm}=.24 \mathrm{~km}$ ) photography. In addition, numerous frames of hand-held oblique photographs were acquired with a $35 \mathrm{~mm}$ camera from a light airplane.

The smallest scale photographs of the Red River Flood ( $1: 116,000)$ were obtained by NASA using the RB-57 high-altitude reconnaissance aircraft flying at an altitude of approximately 58,000 feet $(18,000 \mathrm{~m})$. A precision metric mapping camera with a 6-inch (150 mm) focal-length lens, and 9-inch wide Kodak Aerochrome Infrared film, type 2443 (CIR) was used. Although this mission was flown by NASA, similar photography at scales as small as $1: 80,000$ to $1: 90,000$ could be obtained through commercial sources. Typical frames of small-scale photography are shown by Figures 3 and 4 .

Two versions of medium-scale photography were obtained by contract with a private aerial survey firm. A metric mapping camera with a 6-inch lens and CIR film was used to acquire photographs of scales of $1: 48,000$ and $1: 24,000$. Examples of - medium-scale flood photographs are shown by Figures 5, 6, and 7 .

Hand-held photographs were taken from a light aircraft flying approximately 1,000 feet $(300 \mathrm{~m})$ above the ground. A $35 \mathrm{~mm}$ single-lens reflex camera with Kodak Ektachrome Infrared film and a number 12 (yellow) filter was used. Unlike the large aerial cameras which produce large format vertical photographs, the $35 \mathrm{~mm}$ system was used to acquire reconnaissancetype oblique photographs for detailed looks at specific areas, as shown on Figure 8 . The ground location of figures 3 through 8 is shown by Figure 9 .

The approximate number of aerial photographs at various scales required for full coverage of a regign the size of Cass County, North Dakota $\left(1,700 \mathrm{mi}^{2}\right.$ or $\left.4,410 \mathrm{~km}^{2}\right)$ is shown by Figure 10 .

Although this report does not deal directly with the matter of acquiring CIR aerial photography, a few general comments on the subject should be made. Based upon past experiences, 1:24,000 scale photography is a good choice for assessing damage to agriculture. For maximum usefulness in interpreting flood damage to crops, the photography should be flown soon after most of the floodwater has drained from the fields rather than at the peak of flooding. Costs vary considerably, depending upon the extent of flooding, the availability and capabilities of survey aircraft, photographic specifications, and other factors, but can generally be expected to range between one and three thousand dollars for complete $1: 24,000$ scale CIR coverage of an area the size of the Red River Valley Flood. 


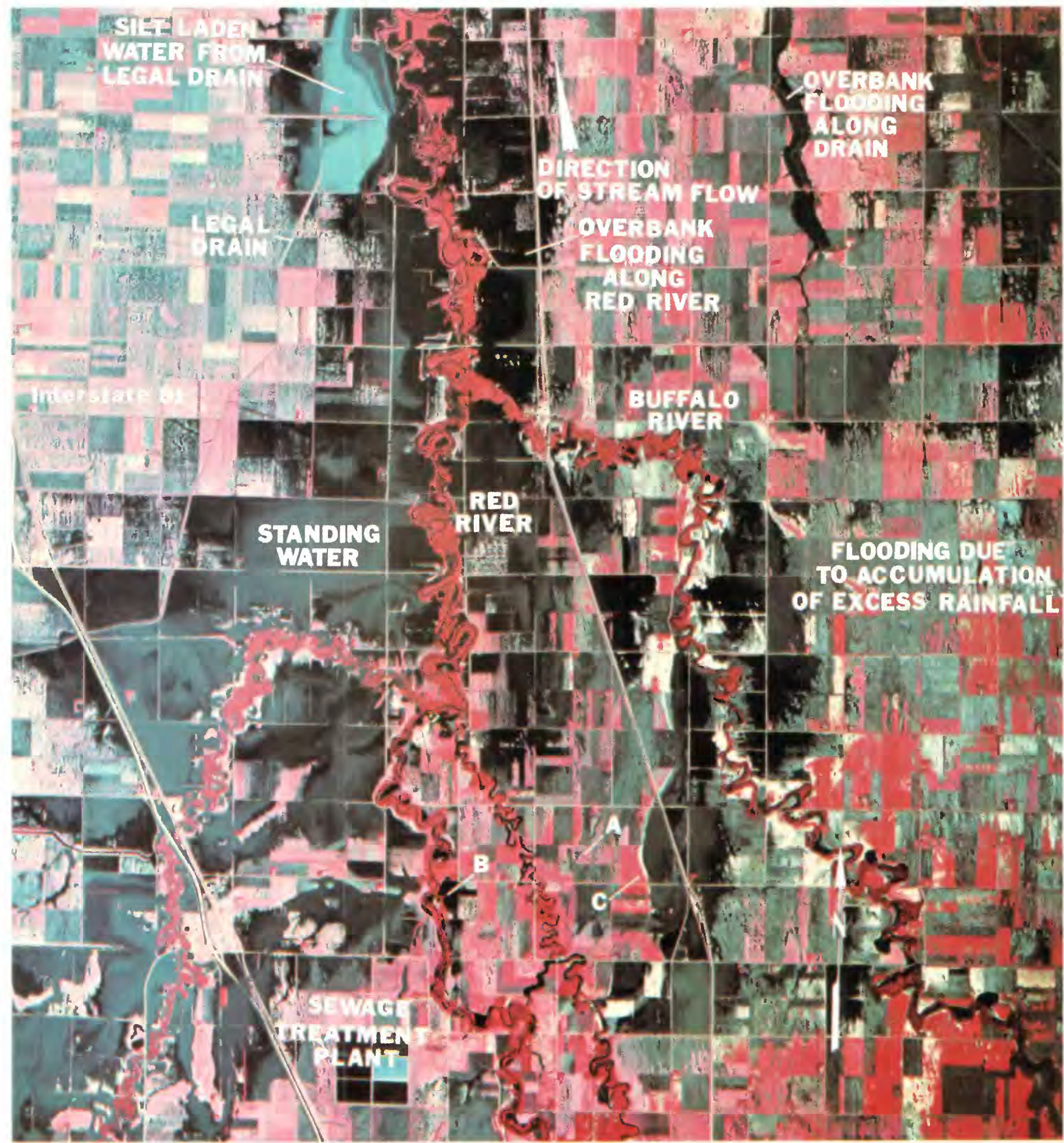

Figure 4. Small scale $(1: 118,000)$ color-infrared aerial photograph, acquired July 10, 1975, of the Red River north of Fargo, N. Dak. (A) Example of complex flood damage to an agricultural field. Plants in some portions of the field have been destroyed while other areas appear relatively unaffected. This field can be located on Figure 6, taken at a later date and at a different scale. (B) Uniform dark tones area typical of standing water, in this case due to overbank flooding from the Red River. Compare with Figure 6 on which the appearance of the ground after surface water has drained can be seen. (C) White linear feature typical of a debris line along the edge of a totally inundated area. Standing water is to the right, apparently living vegetation to the left. Compare with Figure 6. 


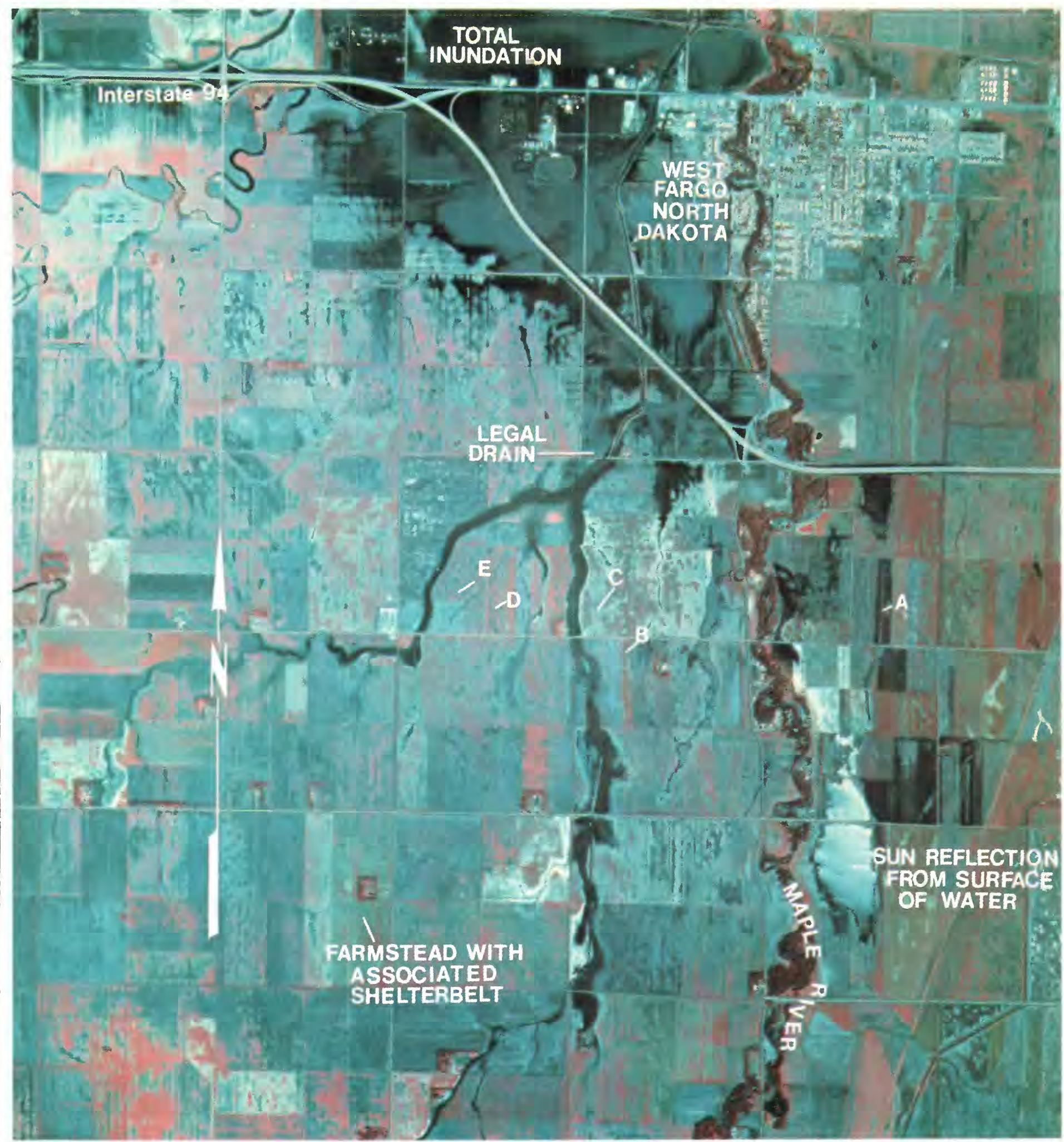

Figure 5. Medium scale $(1: 48,000)$ color infrared photograph, acquired July 13,1975 , of an area southwest of West Fargo, N. Dak. Compare the level of detail visible at this scale to that seen on the smaller scale image, Figure 3. (Notice that the acquisition dates are different.) (A) Evidence of recent, post-flood tillage. Surface flooding often leaves a thin deposit of light toned sediment on the soil. When the soil is turned, darker soil is exposed to view. (B) Damaged corn. (C) Damaged barley. This field was eventually salvage harvested. (D) Damaged wheat. (E) Damaged wheat which appears to be less mature than the field at $D$, as evidenced by the less dense canopy. 


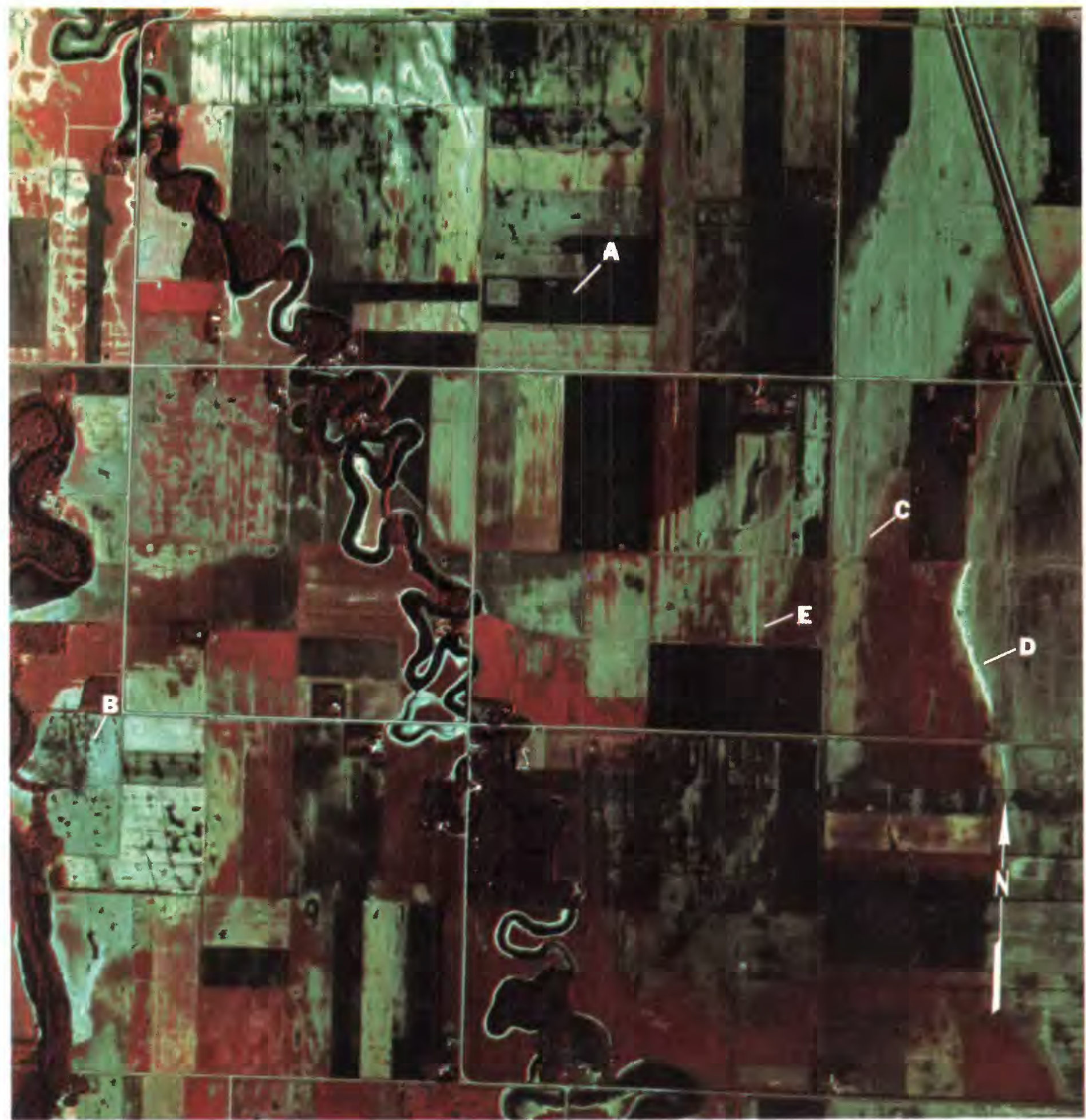

Figure 6. Medium scale (1:24,000) photograph acquired July 17, 1975, over the Buffalo River north of Fargo, N. Dak. At this scale, many small details are visible. Compare the overall appearance with undamaged landscape, Figure 7. (A) Field being cultivated following inundation and subsequent drying. The darker portions of the field are typical of the appearance of the region's lacustrine soils after the silt-covered surface has been tilled. Notice evidence of the tractor turning in midfield. (B) Region of total inundation shown in Figure 4, area B. (C) The sharp boundary between the silt-coated soil (grey tones) and the surviving crop (red tone) indicates the limit of inundation in this area. Distinctive differences in image colors often serve as the basis for peak inundation limit after the flood has receded. (D) A line of debris, principally straw and other dead plant material, indicating the limit of inundation. (E) Field illustrating complex damage pattern. Shown in Figure 4, area A. 


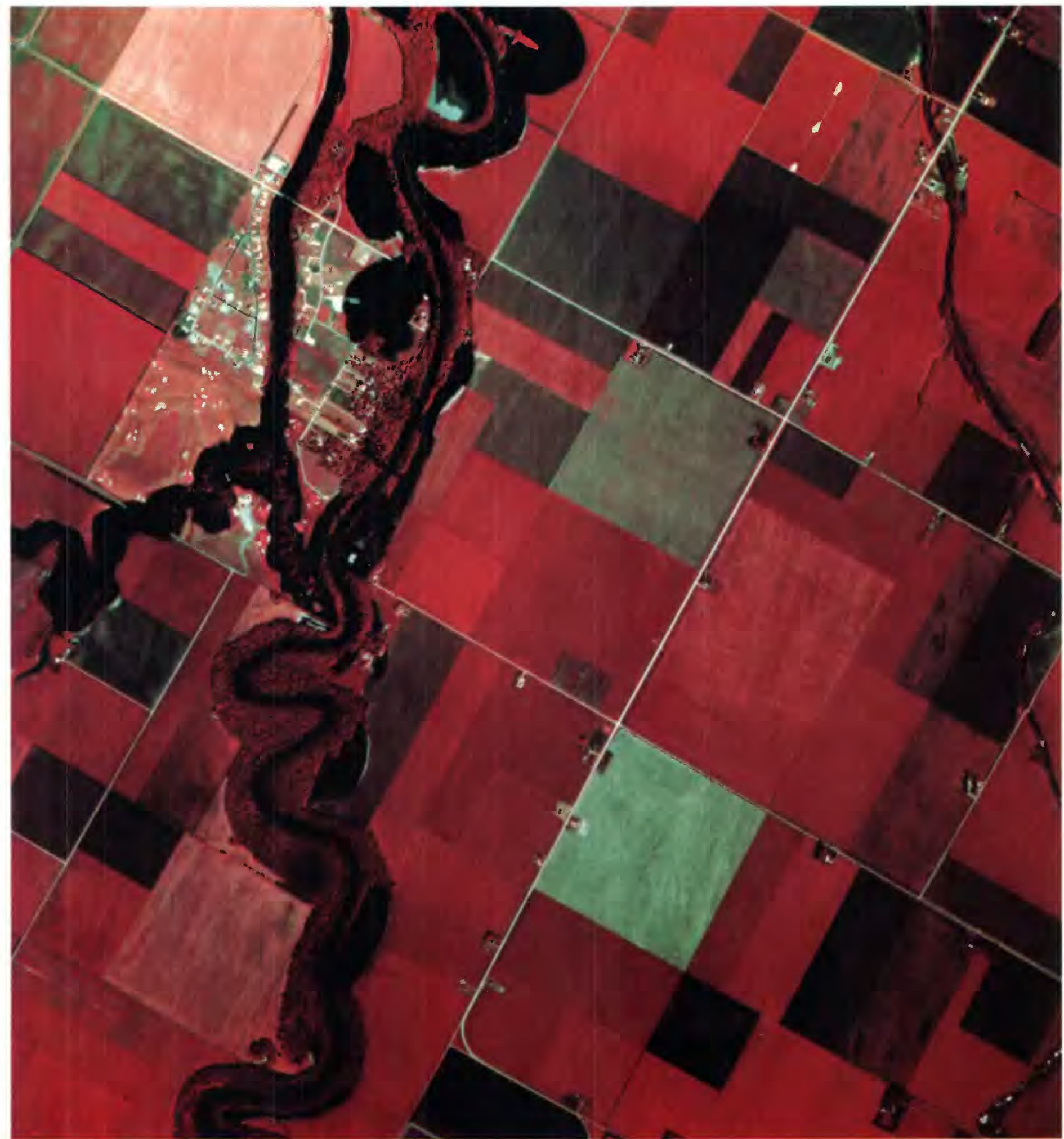

Figure 7. Medium scale $(1: 24,000)$ photograph, acquired July 17,1975 , of an area along the Red River near Grand Forks, N. Dak., showing essentially undamaged crops. Compare the relatively uniform appearance of healthy fields on this image to the complicated, complex mixture of tones of the damaged fields on Figure 6. 


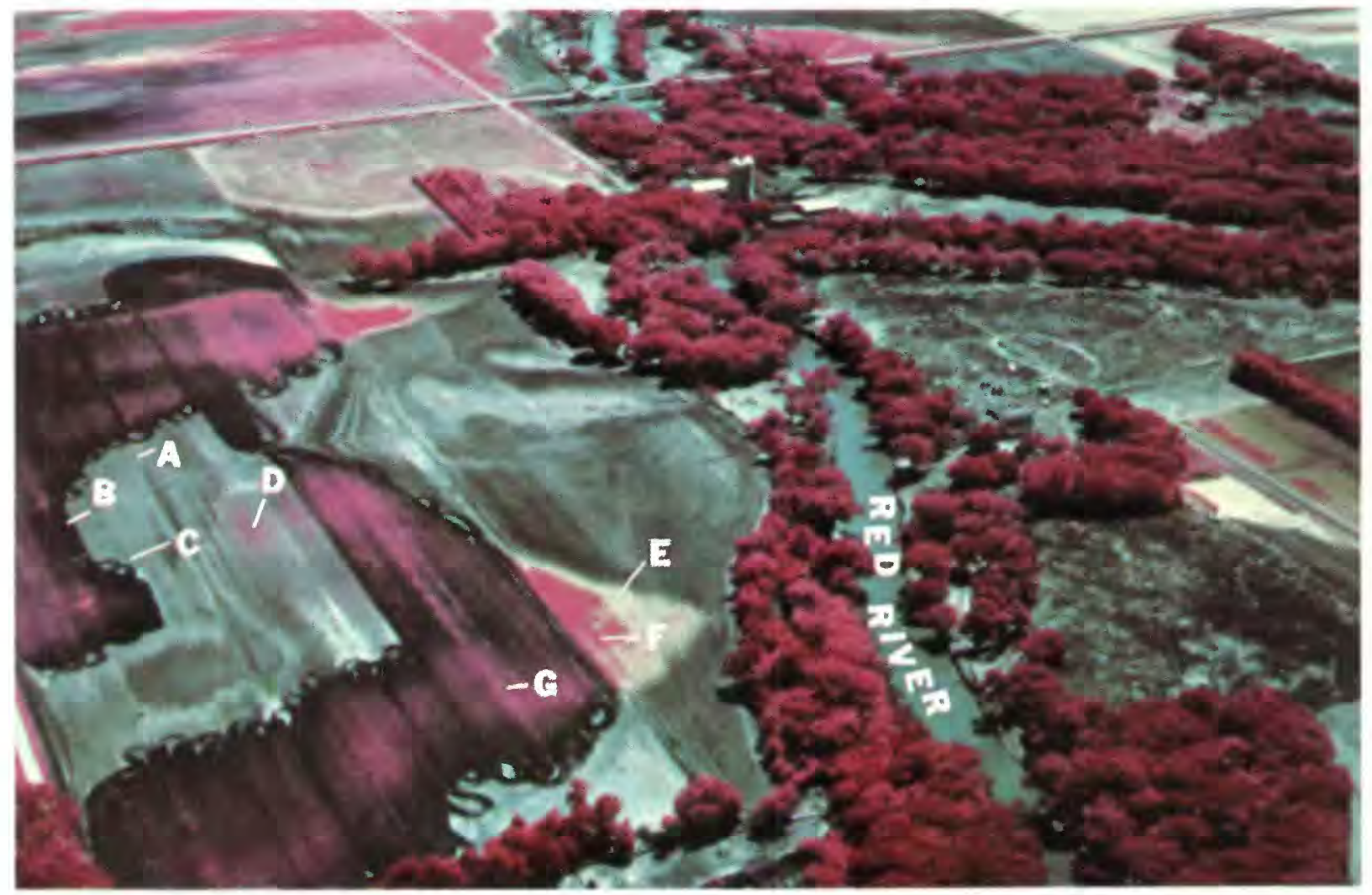

Figure 8. Hand-held oblique color-infrared photograph, acquired July 25, 1975, from a low-flying light airplane. View is looking SSE. This type of photography is useful for gathering information on specific areas at low cost. (A) Typical color of silt-covered soil surface following inundation by overbank flood water. Compare to image appearance of freshly tilled soil shown at "B". (B) Uniform dark appearance of freshly tilled lacustrine soils. Without the thin deposit of silt, these soils appear a nearly uniform black. (C) Marks left by tillage implement as it turns to begin another row of cultivation. Notice the change in soil color. Such evidence is useful in determining the true soil color as it appears on color infrared film. (D) Living vegetation growing in silt-covered soil. (E) Yellow tones indicative of vegetation which has died as a result of flooding. (F) Living vegetation, probably a surviving patch of small grain. (G) Living sugar beets which have been cultivated in order to help dry excess water in the root zone. 


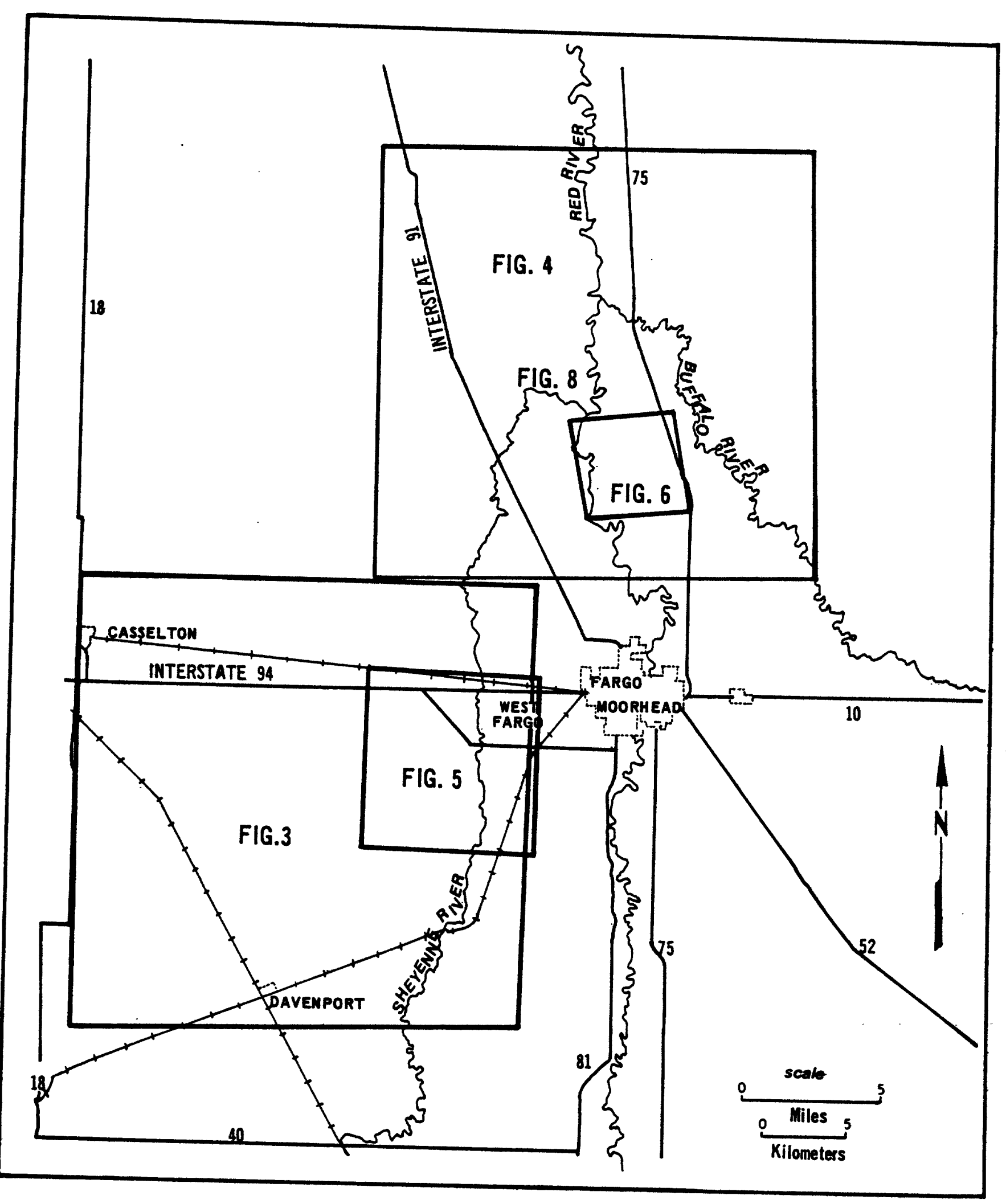

Figure 9. Location map for areas shown in Figures 3-6, 8. 


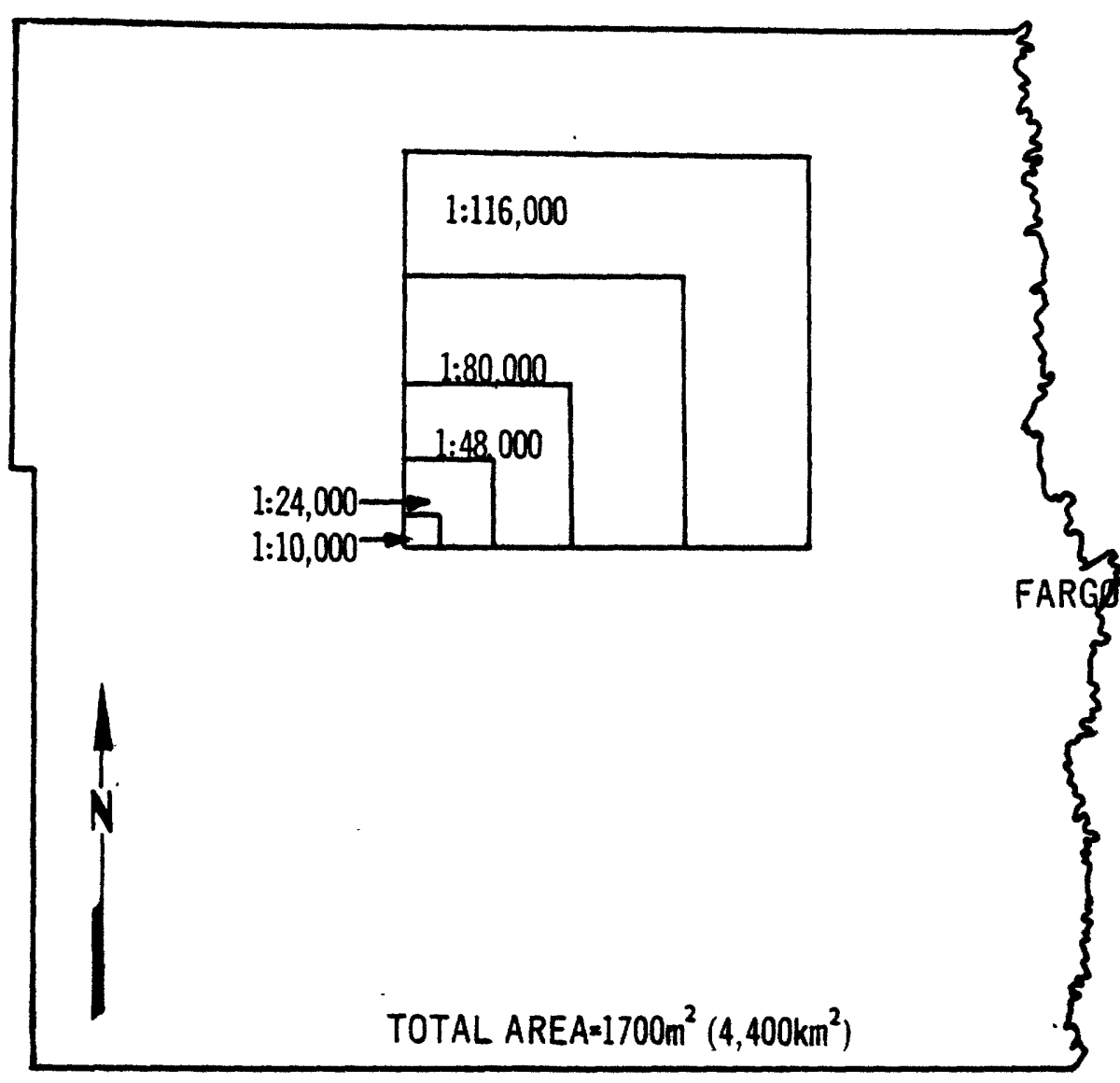

CASS COUNTY N.D.

\begin{tabular}{|c|c|c|c|}
\hline PHOTO SCALE & $\begin{array}{l}\text { APPROXIMATE GROUND AREA } \\
\text { RECORDED ON EACH PHOTOGRAPH }\end{array}$ & \multicolumn{2}{|c|}{$\begin{array}{l}\text { APPROXIMATE NUMBER OF PHOTOGRAPHS } \\
\text { REQUIRED FOR COMPLETE COUNTY COVERAGE }\end{array}$} \\
\hline & & Nonstereo & Stereo ${ }^{2 J}$ \\
\hline $\begin{array}{r}1: 10,000 \\
1: 24,000 \\
1: 48,000 \\
1: 80,000 \\
1: 116,000\end{array}$ & $\begin{array}{l}2 \text { sq. mi. } \\
12 \\
46 \\
129 \\
272\end{array}$ & $\begin{array}{r}866 \\
151 \\
38 \\
14 \\
6\end{array}$ & $\begin{array}{r}3092 \\
538 \\
134 \\
48 \\
23\end{array}$ \\
\hline
\end{tabular}

Figure 10. Aerial photographic coverage requirements at various scales for an area the size of Cass County, North Dakota (1700m2 or $4400 \mathrm{ha} 2)$. The approximate area coverage of a single frame is shown to scale and the approximate total number of photographs required for complete county coverage in both non-stereo and stereo is tabulated for each scale.

$1 /$ Assuming nominal $9 \times 9$ inch photographic size.

2/ Assuming nominal $60 \%$ forward and $30 \%$ side overlaps. 


\section{COLOR INFRARED FILM}

Because this document emphasizes the interpretation of CIR photographs, a brief description of this type of film is appropriate. Additional information can be found by consulting the literature mentioned in selected references section.

Both normal color film and CIR film consist of three separate layers of emulsion on a clear base material. In normal color film, one emulsion layer is sensitive to blue light, one to green light, and one to red light. The images recorded on the three emulsion layers of normal color film combine in the final image to form colors which closely match those of the original subject. CIR film, sometimes referred to as "falsecolor film" also produces combinations of blue, green, and red in the final image; but the blue color results from exposure by green light, the green color from exposure by red light, and red color by exposure of the infrared sensitive layer by infrared energy (Figure 11). Actually all three layers of CIR film are also sensitive to blue light. For this reason, the film is always exposed through a minus-blue (yellow) filter which eliminates blue light before it reaches the film. It must be remembered that the infrared energy needed to expose the infrared sensitive layer is reflected energy and is not heat energy. Heat energy does not enter into the image forming process of CIR film.

One of the most important features of CIR film is the manner in which vegetation is recorded. Healthy green plants appear in shades of red, because healthy plants reflect sunlight strongly in the photographic infrared region (therefore strongly exposing the infrared sensitive layer) while simultaneously reflecting relatively little energy in the visible region (therefore offering little exposure to the green and red sensitive layers). For all practical purposes, living healthy vegetation is the only natural source of high-infrared reflection coupled with low-visible reflection. Therefore, it is the only natural feature to appear red on color-infrared photographs. Because of the unique reflectance characteristic of healthy vegetation, the film was originally used by the military to differentiate between real vegetation and painted camouflage material.

A typical frame of CIR aerial photography consists of many colors and patterns as shown on figures 3 through 8 . Red tones dominate when the photograph is taken of highly vegetated area at a time of the year when vegetation is green and healthy. In contrast, an image acquired during the winter months or of an area where healthy vegetation is sparse would show little, if any, red. 


\section{FILM COMPARISON}

\section{NORMAL COLOR FILM COLOR INERARED FILM}

\begin{tabular}{|c||c|c|c|}
\hline $\begin{array}{c}\text { FILN SENSITIVITY } \\
\text { IN EMULSION LAYERS }\end{array}$ & $\begin{array}{c}\text { COLOR ON PHOTO } \\
\text { AFTER PROCESSING }\end{array}$ & $\begin{array}{c}\text { FILM SENSITIVITY } \\
\text { IN EMULSION LAYERS }\end{array}$ & $\begin{array}{c}\text { COLOR ON PHOTO } \\
\text { AFTER PROCESSING }\end{array}$ \\
\hline BLUE & BLUE & BUUIE UIGGHS & BLUE \\
\hline GREEN & GREEN & GREEN & GREEN \\
\hline RED & RED & RED & RED \\
\hline & & INFRARED & \\
\hline
\end{tabular}

Figure 11. Film sensitivities and final image color of normal color and color-infrared films. $1 /$ Blue light absorbed by yellow filter. 
Another unique and valuable aspect of CIR photography results from the fact that plants do not reflect strongly in the photographic infrared when they are severely stressed or have died, and as a result, no longer appear red on the photographs in contrast to normal, healthy vegetation. The reasons behind this phenomena are complicated, yet the ability to distinguish between healthy and stressed or dead vegetation by using color infrared film is extremely important for vegetation analysis. This characteristic is particularly useful in determining crop damage due to flooding, that is, separating healthy from water damaged crops.

Generalizations about the photographic appearance of other features commonly found on the agricultural landscape can also be made on the basis of past experience. Clear water, for example, usually appears very dark blue or black. Extremely muddy or turbid water, on the other hand, appears light to medium blue. Fresh grain stubble appears very light or almost white; whereas clean plowed fields of dark soil usually appear dark blue. The relationship between objects or conditions on the ground and their appearance on aerial photographs can be established for particular sets of circumstances, and a knowledge of this relationship provides the basis for photographic interpretation.

\section{USING CIR PHOTOGRAPHY FOR DETERMINING CROP LOSS}

According to the official Adjuster's Manual issued by the Federal Crop Insurance Corporation (FCIC), the mandatory on-site farm damage inspection and adjustment is a very labor intensive and costly task (U.S. Dept. Agric., 1964). Adjusters are instructed to impartially gather all data relevant to assessing actual loss. Their role is principally one of a fact finder, but because of the complex nature of many crop damage situations (including flooding), they must often rely on their own best judgment to evaluate crop damage when quanitative data on exact production loss is not obtainable.

One of the principal determinations which the adjusters make is an appraisal of remaining potential production of a field which has been claimed by the producer as having been damaged. In the case of the Red River Valley Flood, as in other damage situations, the producer must notify the FCIC and request a preliminary inspection. As soon as possible after receipt of the claim, an adjuster visits the farm, and accompanied by the producer, inspects the damage and estimates production loss.

For those fields which have obviously been totally destroyed by flooding, assessing the loss is relatively simple and generally uncontroversial. In situations where a field was only partially 
damaged, the adjuster must determine what portion of the insured production has been lost and what portion potentially still remains. This determination is often extremely difficult to make, especially early in the growing season when the plants are small and immature. In order to determine the production from a field, the yield must be estimated and that value multiplied by the crop area of the field. Expressed mathematically, the relationship is:

$$
\mathrm{P}=\mathrm{Y} \cdot \mathrm{A}
$$

where $P=$ total field production; $Y=$ average yield per unit area; and $\mathrm{A}=$ the crop area.

Estimating the yield component is often difficult, especially with young plants. Current techniques call for statistical sampling in various parts of the damaged field. The minimum number of small sample plots to be examined within a field varies according to the field size. For example, fields of from 10 to 99 acres must have a minimum of 5 samples evaluated for determining yield; 100-135 acres must have at least 6 ; $136-170$ acres must have at least 7 , and so forth on up to 15 sample plots for fields 415 acres or 1arger. (U.S. Dept. Agric., 1964).

Yield determination procedures for small grains necessitate a close inspection of the individual plants in the sample, observing such attributes as spacing and number of tillers, if any. In the case of more mature small grains, the yield component is determined by counting the number of plants in the sample, the number of heads per plant, and the number of grain kernels per head.

Since the determinants of yield are drawn from detailed anatomic and morphological observations of individual plants, CIR aerial photography cannot be used to directly obtain the information currently required to calculate expected yield. Research is being conducted to develop new techniques for relating image appearance to yield, but no proven techniques for direct determination are available at this time. However, it is reasonable to expect improvement in estimating the yield component for some spatially complex damage situations by using the photograph to partition the damaged field into strata for better sample allocation.

Currently the acreage component of production is determined by actual measurement where possible. Tapes or wheel-type measurement tools are used in order to determine the damaged (or undamaged) area to the nearest acre or less. Damaged area 
measurement in instances where the pattern of damage is relatively uniform, such as in the case of a general drought or total flood inundation, can usually be accomplished with conventional techniques. In some cases of excess water damage, field damage patterns can be extremely complex. When fields contain a spatially complex mixture of damaged and undamaged plants, it becomes impractical to measure every small patch of surviving crop in order to arrive at a total acreage figure. In such cases, field sketches must be made based on visual observations in lieu of more quantitative measurements. The field sketches of damaged areas are later measured using conventional map area measurement techniques. The accuracy of the area determinations made in this way are directly related to the accuracy of the original field sketches.

To illustrate the use of CIR photography in determining the acreage component in production estimation, a site in Cass County, North Dakota which exhibited a wide range of flood effects was selected (Figure 12). Most agricultural fields in the demonstration site were generally inaccessible and from the perspective afforded by a roadside vantage point, were often unmappable as well (Figure 13). Assuming the availability of post flood CIR photography, the surviving vegetation in each field can be readily delineated and measured using one of several standard techniques. One possible procedure would be to first delineate the surviving portions of the stand onto an overlay and then measure the delineated areas. Another method would be to eliminate the separate delineation phase and combine the tasks of identification and measurement concurrently.

The "delineate and measure" approach is somewhat similar to the conventional method in that a "map" showing surviving stand areas is prepared and subsequently measured. Using aerial photographs, however, the often difficult field sketching tasks are replaced by a photographic interpretation technique.

Summarizing the procedure required, a piece of transparent overlay material is fastened to the photograph of the area to be interpreted. The surviving portions of each field are indentified and delineated on the overlay. This is a relatively simple task since only normal, apparently healthy vegetation appears red on color-infrared photography. Careful attention must be given to limiting the interpretation to actual cropped fields, avoiding non-agricultural vegetation areas (shelterbelts, farmyards, roadside weeds, etc.) in the delineations.

Figure 14A illustrates one interpreter's results and represents what can typically be expected from an individual with minimum interpretation experience such as one day's training in colorinfrared interpretation fundamentals. 


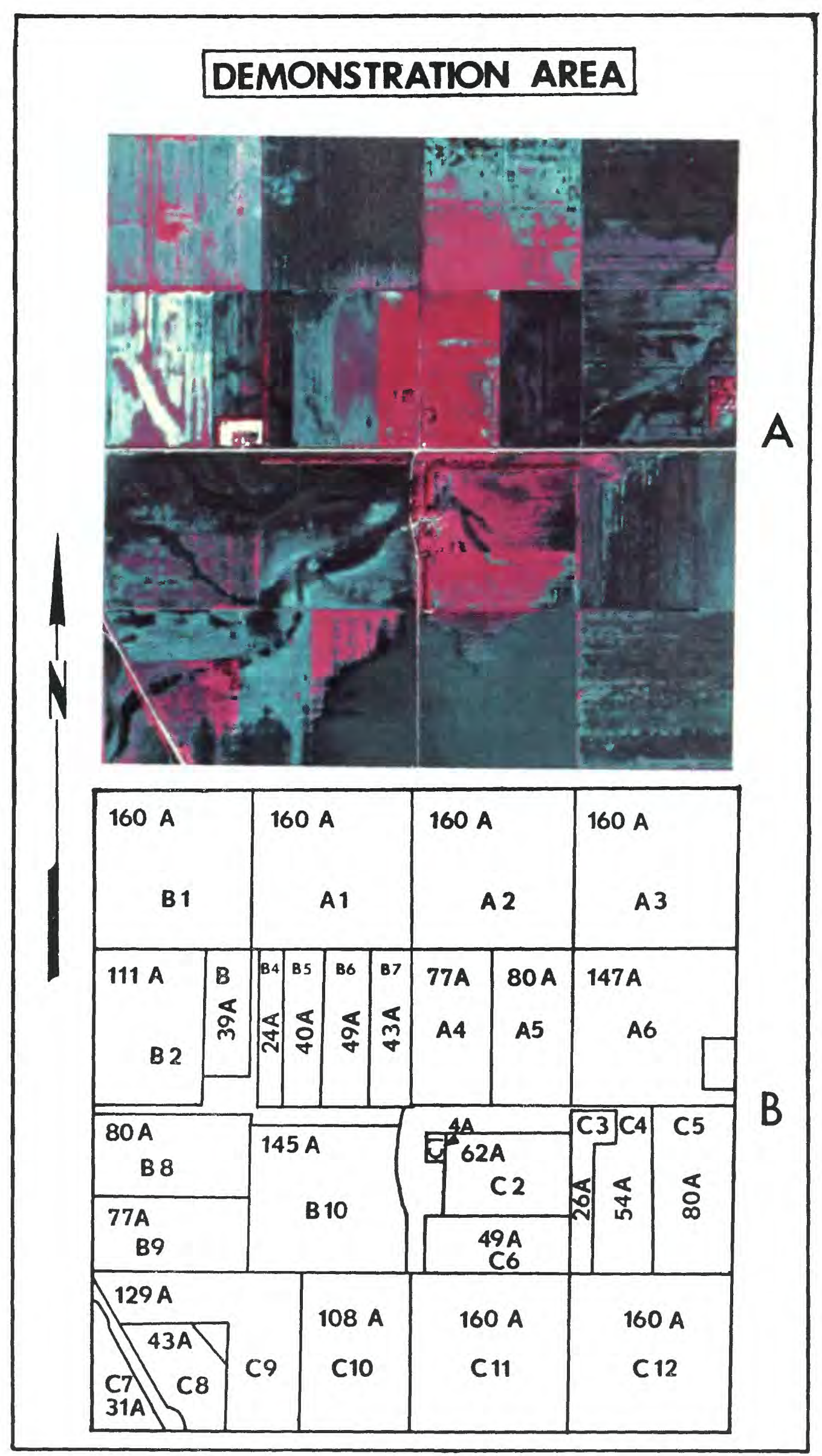

Figure 12. (A) Color infrared aerial photograph acquired July 12, 1975, of the 4 square mile (10 $\mathrm{km} 2)$ demonstration area. (B) Index diagram for demonstration area. Farm A has a total of 784 acres (317 ha) under cultivation; Farm B, 768 acres (311 ha) cultivated; Farm C, 906 acres (367 ha) cultivated. 


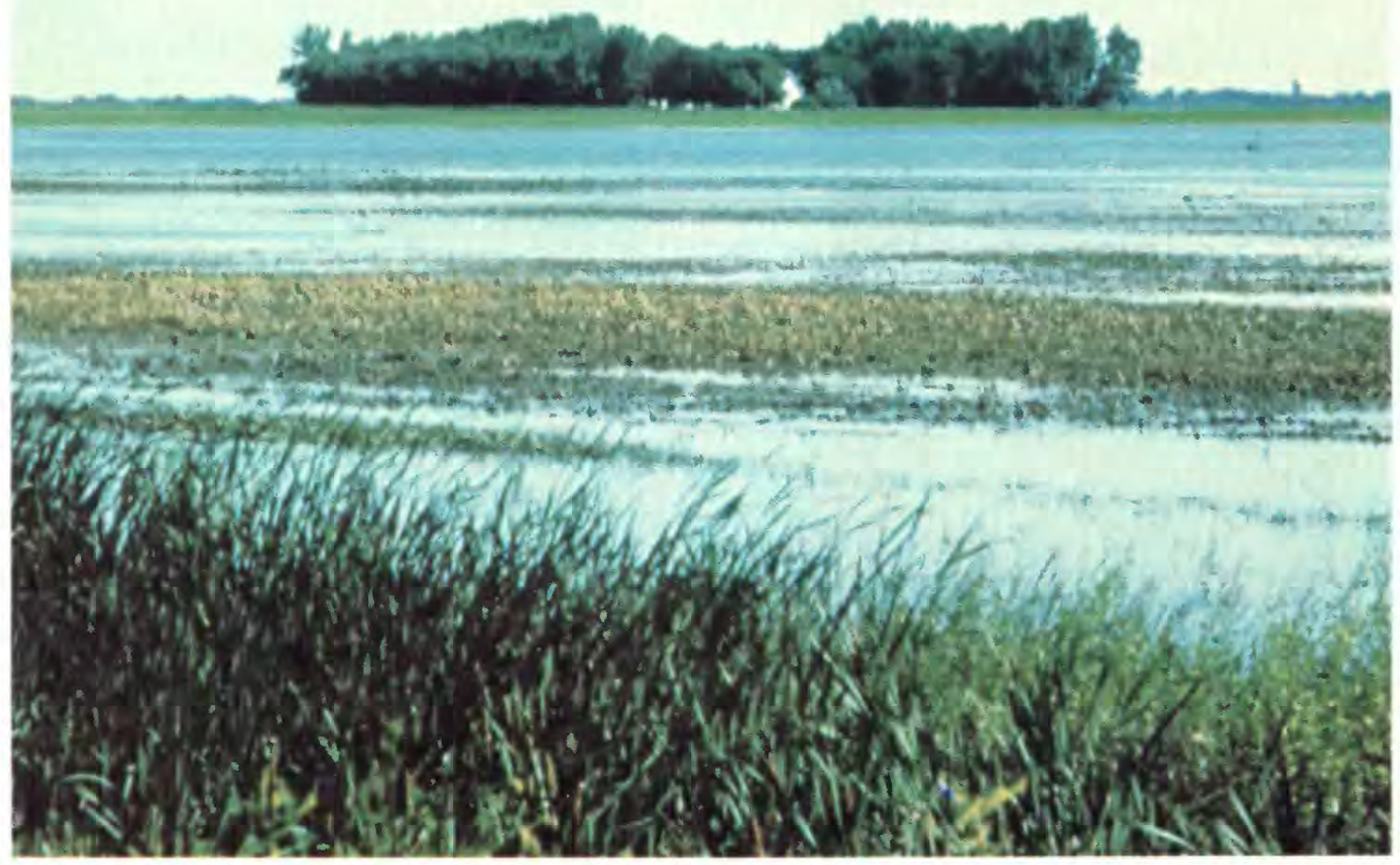

Figure 13. Typical appearance of flooded cropland in the vicinity of the demonstration area. From the ground perspective it is difficult to accurately sketch crops which may have survived the flooding. 


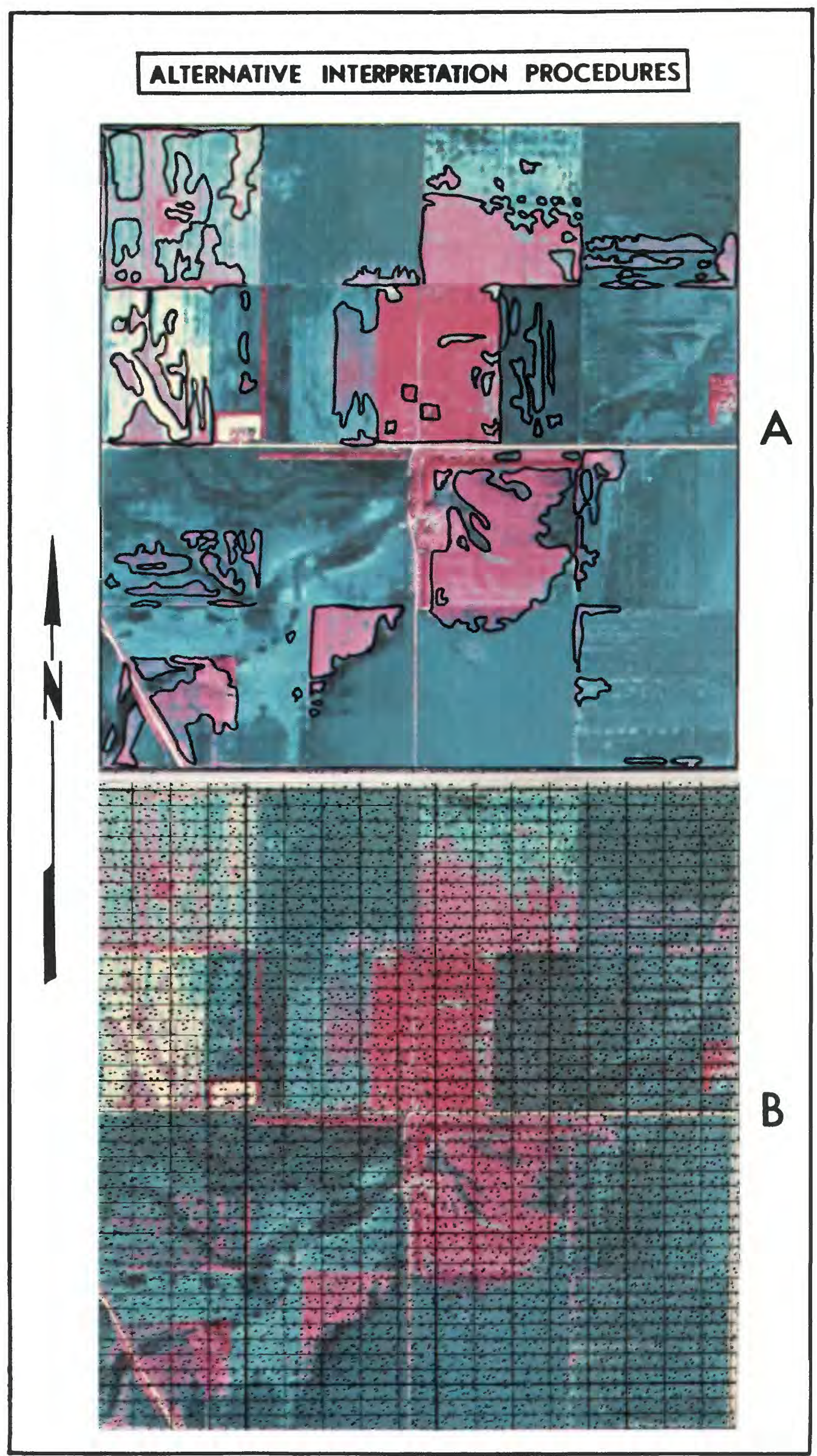

Figure 14. (A) Aerial photograph of demonstration area with superimposed delineation of relatively undamaged (surviving) portions of crop stands. Boundaries determined by interpretation and subsequently measured. (B) Aerial photograph of demonstration area with superimposed dot grid used to calculate area of undamaged crops directly from photograph. 
Notice that in field B2, the surviving vegetation is found in a matrix of light toned material. This condition is typical of headed barley fields that have been partially destroyed by inundation. The light toned areas are portions of the stand which have been adversely affected, causing the barley to lose its normal green color as seen on the ground and lose its red color on the color-infrared image. In contrast, field B9 displays the red tones of surviving vegetation against a background of dark tones, indicating that the background material is not a layer of dead plant matter but bare soil or mud.

Even though background material may vary from a nearly continuous thick layer of dead plant material which completely obliterates a view of the soil, to shallow standing water as in parts of field CIO, the interpreter needs only to delineate the red tones of living vegetation. In simpliest terms, the interpretation procedure reduces to a choice between surviving crops or other material.

The matter of deciding how "red" an area must be in order to be declared surviving vegetation often requires careful consideration. As a general rule, very small or extremely indistinct reddish areas should not be delineated as shown by the delineations in fields $\mathrm{Cl2}$, $\mathrm{A6}, \mathrm{B} 5$, and $\mathrm{C} 11$.

When the delineation is complete, the area of surviving vegetation is determined by standard map area measurement techniques, and this value is recorded on a per field basis. of the several area measurement techniques available, the dot grid method is probably most efficient in this particular case because of the irregularity and complexity of the delineations to be measured. Table 1 , Columns $C$ and $D$, 1ists the results of the per field area measurement using the method just discussed. Columns $E$ and $F$ show the results of using the slightly different method described in the next paragraphs.

An examination of figure 14A reveals that areas of surviving vegetation are usually distinct and well defined although often complex or highly dissected. As an alternative to the "delineated measure" method, a dot grid can be used directly on the photograph to measure these self-defined areas of surviving vegetation (Figure 14B).

Careful attention must be given to properly locate individual field boundaries in order for a count to be made of the number of dots falling on red tones in each field. The dot count must then be converted to an area value using standard conversion factor procedures. (Table 1 , columns $E$ and F). 
Table 1.--Interpretation results ${ }^{\prime \prime}$

Delineation Method Direct Count Method

$\begin{array}{llllll}\text { A } & \text { B } & \text { C } & \text { D } & \text { E } & \text { F }\end{array}$

Field Field size Remaining Percent Remaining Percent

ID in stand loss stand loss

acres in acres in acres

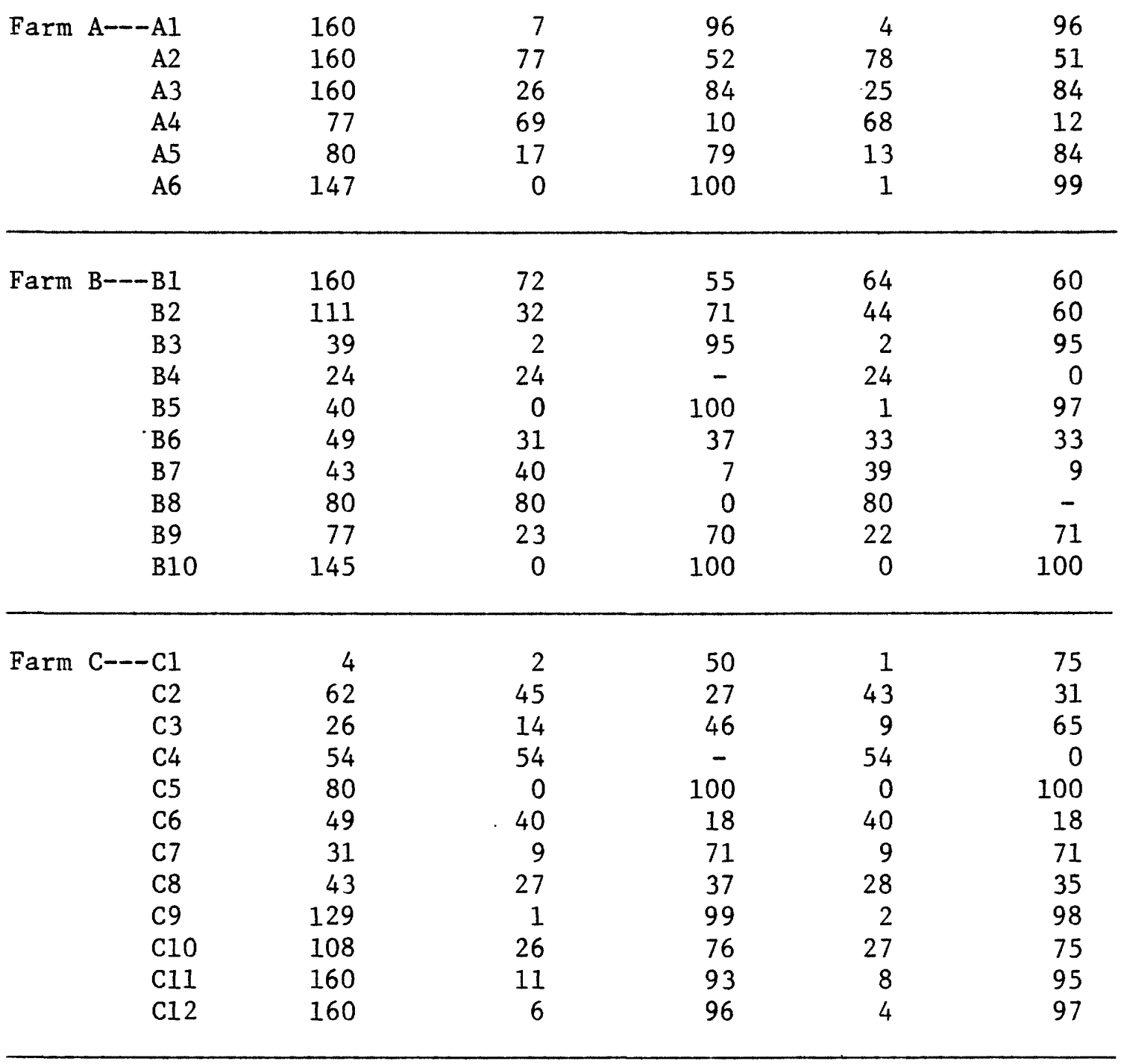

$1 /$ The hypothesis that both methods are of uniform effectiveness cannot be rejected according to results of the paired $t$ statistical test at the .01 probability level. 
Table 1 shows that the alternative approaches to surviving crop area estimation produce nearly similar values; statistically, the results are not significantly different. Where differences exist for a particular field, the percent loss figure generated using the direct dot count method is usually slightly higher. An examination of several individual field results indicates some possible reasons for the variations.

Field A5 shows a five percent difference in interpreted percent loss: 79 percent using the delineation procedure versus 84 percent loss using the direct dot count method. The red tones in this field are relatively indistinct, thus requiring more subjective judgment than is required on fields C10 or A2 where the areas of surviving vegetation are more distinct. The difference in this case can probably be explained in terms of the interpreters' decisions as to what constitutes surviving vegetation and not so much the methodology, per se.

In general, there appears to be a trend towards slightly higher values for surviving vegetation areas using the delineation approach. The results for fields $\mathrm{A} 4, \mathrm{~B} 1, \mathrm{C} 2, \mathrm{C} 3$, and $\mathrm{C} 11$ for example, provide evidence of an interpreter's tendency to be slightly liberal in defining areas of surviving vegetation. The direct count method appears to be somewhat more selective in areas with finely disected, intricate boundaries between surviving vegetation and "other".

Both methods require approximately 12-15 minutes of analysis time per square mile $\left(1.6 \mathrm{~km}^{2}\right)$ which suggests that the time element is not a significant factor in differentiating between the two techniques. However, the delineation approach has one potentially useful advantage in that an overlay is produced which serves as a graphic record of the interpretation results. If an identification or measurement problem is suspected, the delineation overlay can be used as a check of the original identifications.

A comparison between an actual field damage appraisal form and the photographic record for the same fields is shown in Figure 15. Loss of stand estimates are also shown for the conventional ground sketching technique and CIR interpretation techniques. Although in this particular case the farmer's estimates were slightly higher than the interpreted estimates, an examination of other conventional field reports revealed that the ground estimates ranged both above and below the photo interpretive results.

In summary, an appraisal procedure which uses CIR photo interpretation techniques in conjunction with ground sampling can produce more accurate estimates of remaining production in situations similar to the Red River Valley Flood than can be 


\section{A}

B

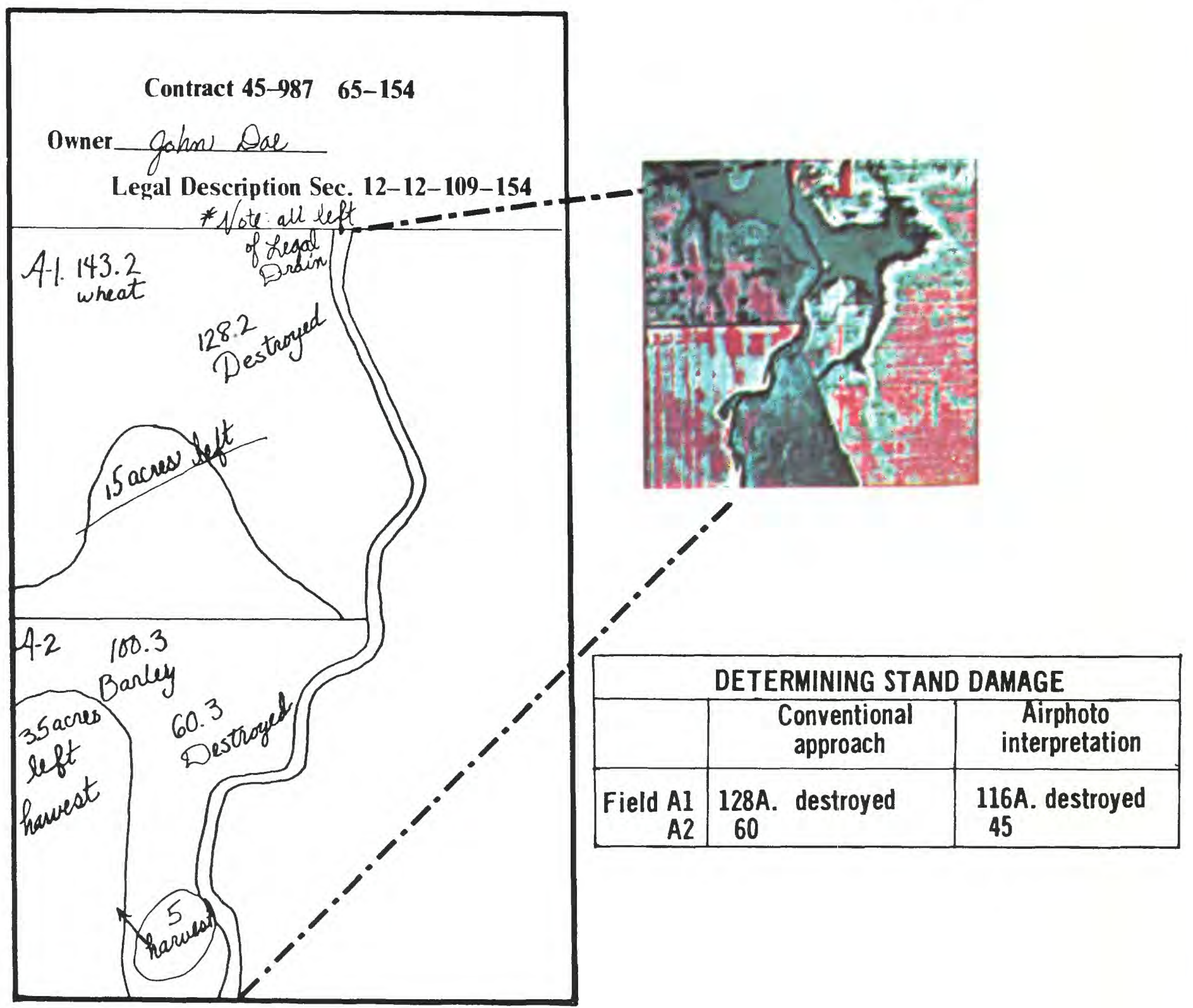

Figure 15. Comparison between conventional field sketch and a CIR aerial photograph of same area. (A) Field sketch based on an ASCS "Application for Disaster Credit" form filed following the Red River Valley Flood. The name, contract number, and legal description has been changed, but the sketch is shown as submitted by the farmer on July 21, 1975. (B) Color infrared photograph accurately records the spatial distribution of surviving vegetation with the two fields. 
obtained relying solely on conventional techniques, primarily because of greater accuracy in determining the remaining crop area.

\section{CONCLUS IONS}

This investigation and others have demonstrated the value of using CIR aerial photographs to help assess flood damage to agriculture. In summary:

1) CIR aerial photography has the capability to record information useful in assessing flood damage. As shown by examples in this report, such things as:

- inundated areas

- bare soil, muddy fields

- living and damaged crops

- dead vegetation

- natural vegetation areas, farmsteads

- debris, damage to roads

- areas of sedimentation

- post flood harvest activity

can be located and identified.

2) In nearly all cases, useful information can be derived from suitable CIR photographs by individuals with a minimum of training and airphoto interpretation experience.

3) Airphoto interpretation techniques should be used in conjunction with ground surveys and sampling, not in lieu of conventional procedures. 


\section{LITERATURE CITED}

Lindskov, K. L., 1975 Data summary of June-July 1975 floods in eastern North Dakota and northwestern Minnesota: U.S. Geol. Survey Open-File Report 75-565, 15 p.

U.S. Department of Agriculture, 1964, Adjuster's Handbook, Fed. Crop Insur. Corp., USDA.

U.S. Department of Agriculture, 1971, The look of our land: An airphoto atlas of the rural United States: The plains and prairies, Econ. Res. Service, Agric. Handbook 419, $84 \mathrm{p}$.

\section{SELECTED ADDITIONAL REFERENCES}

Information related to the nature and property of colorinfrared film can be found in the following publications:

Fritz, N. L., 1967, Optimum methods for using infrared-sensitive color film, in 33rd Ann. Meeting Soc. Photogramm. Proc.: Washington, D.C., March 10, 1976.

Knipling, E. B., 1969, Leaf reflectance and image formation on color-infrared film, in Johnson, P. L., ed., Remote sensing in ecology: Athens, Ga., Georgia Univ. Press, 244 p.

Pease, R. W., and Bowden, L. W., 1969, Making color-infrared film a more effective high-altitude remote sensor: Remote Sensing of Environment, v. 1, p. 23-30.

The following references contain general information about flood mapping and damage assessment using remote sensing techniques:

Burgess, L. C. N., 1971, Techniques of flood limit determination, in 37th Ann. Meeting Am. Soc. Photogramm. Proc.: Washington, D.C., March 9, 1976.

Deutsch, Morris, and Ruggles, F. H., 1974, Optical data processing and projected applications of the ERTS-1 imagery covering the 1973 Mississippi River Valley Floods, in Earth Resources Satellite Symposium, 3rd, Goddard Space Flight Center, December 1973: National Aeronautics and Space Administration, v. 1 , section B, p. 1167-1188.

Hoyer, B. E., Hallberg, G. R., and Taranik, J. V., 1974, Summary of multispectral flood inundation mapping in Iowa: Iowa Geological Survey, Public Information Circular no. 7, 57 p. 
Meyer, William, and Welch, R. I., author-editors, 1975, Water resources assessment, in Reeves, Robert G., ed.-in-chief, Manual of remote sensing: Falls Church, Virginia: Am. Soc. Photogramm., v. II, p. 1479-1552.

Meyers, V. I., Waltz, F. A., and Smith, J. R., 1973, Remote sensing for evaluating flood damage conditions, the Rapid City, South Dakota Flood, June 9, 1972: South Dakota State Univ., Remote Sensing Institute, Field Inv. Rept. 72-11, 29 p.

Morrison, R. B., and Cooley, M. E., 1973, Assessment of flood damage in Arizona by means of ERTS- 1 imagery, in Proceedings Symposium of Significant Results from ERTS-1, v. 1, p. 755760 .

Piech, K. R., and Walker, J. E., 1972, Thematic mapping of flooded acreage: Photogramm. Eng., v. 38, p. 1081-1090.

U.S. Geological Survey, 1975, U.S. Geological Survey publications on floods: U.S. Geological Survey INF-68-12(R.2), 27 p. 